\title{
Simulation of thermal field dynamics in the erected reinforced concrete structure
}

\author{
Aleksander Stepanov ${ }^{1, *}$, Egor Popandopulo ${ }^{1}$, Artem Romsa ${ }^{1}$, and Matvey Zatonskikh ${ }^{1}$ \\ ${ }^{1}$ Moscow state University of civil Engineering, Yaroslavskoe shosse, 26, Moscow, 129337, Russia
}

\begin{abstract}
During the heat treatment of concrete, temperature field in the structure can be controlled by changing the initial concrete temperature, the heating power of the heating elements, and heat transfer conditions at the surface of the structure. There is the task of finding such heat treatment mode in which the temperature field has the desired characteristics. These characteristics include temperature, rate of rise and temperature gradient. The first step in the solution of the heat treatment operation problem is to create a sufficient point of a mathematical model of the temperature field in the hardening concrete. The second stage should be devoted to the numerical solution of the equations of the model, which allows a computer to determine the temperature field in hardening concrete structure. With this method, you can use a computer to study the dynamics of the temperature field at various modes of heat treatment and to develop the most rational modes without the need for a large series of scientific experiments. For the numerical solution of model equations, a locally onedimensional scheme of the method of full approximation is applied. This scheme is economical, relatively simple to program, does not require a lot of memory, and allows performing calculations on a computer.
\end{abstract}

\section{Introduction}

During the heat treatment of concrete, temperature field in the structure can be controlled by changing the initial concrete temperature, the heating power of the heating elements and heat transfer conditions at the surface of the structure [1-3]. There is the task of finding such heat treatment mode, in which the temperature field has the desired characteristics. These characteristics include temperature, rate of rise and temperature gradient $[16,20]$.

The first step in the solution of the heat treatment operation the problem is to create a sufficient point of a mathematical model of the temperature field in the hardening concrete.

The second stage should be devoted to the numerical solution of the equations of the model, which allows a computer to determine the temperature field in hardening concrete structure. With this method, you can use the computer to study the dynamics of the temperature field at various modes of heat treatment and to develop the most rational modes, without the need for a large series of scientific experiments.For the numerical solution of the model equations applied locally one-dimensional scheme (VOC) total

*Corresponding author: inferno1020@mail.ru 
approximation method [5]. This scheme is economical, relatively simple to program [5] does not require a lot of memory, allowing you to perform calculations on a computer.

\section{Methods}

Replacing the three-dimensional heat equation chain-dimensional equations.

We introduce in $\mathrm{G}$ bound grid with steps $h p$, formed by three families of the $G_{p}$ straight, parallel to the coordinate axes $\mathrm{x}_{\mathrm{p}}$, division points $\mathrm{P}=1,2,3$. Let's consider the problem on the segment $\left[0, \mathrm{t}_{0}\right]$ and divide it by division points

$$
t_{j}=(j-1) \tau ; j=1,-, j_{o}, \tau=\frac{t_{o}}{j_{o}} .
$$

At each interval $\left(t_{0} ; t_{j+1}\right)$ three-dimensional heat equation we replace the chaindimensional equations

$$
\frac{1}{3} \mathrm{c} \frac{\partial u_{p}}{\partial t}=L_{p} u_{p}+f_{p} \text { when } t_{x}+\frac{P-1}{3} \tau \leq t_{j}+\frac{P}{3} \tau
$$

along all lines

$$
G_{p}, P=1,2,3, \sum_{P=1}^{3} f_{p}=f
$$

with the initial conditions

$$
\begin{aligned}
u_{1}\left(\vec{x}, t_{j}\right)= & u\left(\vec{x}, t_{j}\right) ; u_{2}\left(\vec{x}, t_{j}+\frac{1}{3} \tau\right)=u_{1}\left(\vec{x}, t_{j}+\frac{1}{3} \tau\right) \\
& u_{3}\left(\vec{x}, t_{j}+\frac{2}{3} \tau\right)=u_{2}\left(\vec{x}, t_{j}+\frac{2}{3} \tau\right) .
\end{aligned}
$$

The boundary conditions for each equation chains are set at the intersection of the corresponding line $\mathrm{G}_{\mathrm{p}}$ family to the border area.

The equation of heat kinetics similar to replace a chain of equations

$$
\frac{1}{3} \frac{\partial \omega_{\mathrm{P}}}{t}=E_{P}, \quad \sum_{P=1}^{3} E_{P}=E .
$$

You can not do this, you need only follow choby heat contribution to the value $f(\tau)$ during the time $\tau$ is equal to $\left(\mathrm{Q}_{\max }, \mathrm{E}, \tau\right)$ at every point of the field.

Physically replacing the three-dimensional heat equation chain-dimensional equations means that the thermal conductivity of the process occurring in the space is replaced by a sequence of one-dimensional processes coordinate directions.

\section{Results}

Let heat-proof partitions installed on the $X_{2}$ and $X_{3}$ directions in point of time ti, i.e. heat spreads only in the direction $\mathrm{X}_{1}$.

At time $\mathrm{t}=t_{j}+\tau$ directions $\mathrm{X}_{1}$ and $\mathrm{X}_{2}$ are changing roles, and at the time $\mathrm{t}=t_{j}+2 \tau$ applies heat only in the direction $\mathrm{X}_{3}$. As a result, at the time $t_{j}+3 \tau$ will have the same temperature distribution, and that at the time $\mathrm{t}=t_{j}+\tau$ in a three-dimensional thermal conductivity. 
For the numerical solution of the model equations on the interval $\left[0, t_{0}\right]$ need to consistently get the decision on the intervals $\left[t_{j}, \mathrm{t}_{\mathrm{j}+1}, \mathrm{j}=1, \ldots, j_{0}\right]$, and the solution of the problem in the previous half-interval is the initial condition for the problem in the future. In turn, the solution of the problem on each half-interval $\left[t_{j}, t_{j+1}\right]$ are conducted sequentially in three directions.

Approximation of the one-dimensional differential equations of a system of linear differential equations along each line of the family $\mathrm{C}$, the system of differential equations

$$
\begin{gathered}
\frac{1}{3} \mathrm{c} \frac{\partial u_{\mathrm{P}}}{\partial t}=L_{P} u_{P}+f_{P}, \\
\frac{1}{3} \frac{\partial \omega_{\mathrm{P}}}{\partial t}=E_{\mathrm{P} .}
\end{gathered}
$$

approximated by a system of linear differential equations

$$
\begin{gathered}
\mathrm{c}_{i} \frac{\widehat{u_{l}}-u}{\tau}=\frac{1}{h_{p}}\left(a_{i+1} \frac{\widehat{u_{l+1}}-\widehat{u_{l}}}{h_{p}}-a_{i} \frac{\widehat{u_{l}}-\widehat{u_{l-1}}}{h_{p}}\right)+f_{p_{i}} ; i=2, \ldots, N-1 ; \\
\frac{\widehat{\omega_{l}}-\omega_{i}}{\tau}=E_{p_{i}}, i=1, \ldots, N ; \\
a_{i+1}=\frac{1}{2}\left(\lambda_{P_{(i+1)}}+\lambda_{P_{i}},\right.
\end{gathered}
$$

where the function arguments are taken in the $\mathrm{i}$-th node on the line at the time $\mathrm{G}_{\mathrm{p}}$

$$
\left(t_{j}+\frac{P-1}{3} \tau\right)
$$

if the symbol $\wedge$ is absent, and at time $\left(t_{j}+\frac{P}{3} \tau\right)$, if the caret is present.

The resulting system comprises $(2 \mathrm{~N}-2)$ linear equations and $2 \mathrm{~N}$ unknowns $-\widehat{u}_{\iota}$

and $\widehat{\omega_{l}}$. The values ui and $\omega$ i solutions known from the previous step. This system is complemented by the two equations poluchaemymy from the boundary conditions at the points of intersection of the line with the boundary of $G_{p}$

$$
\begin{gathered}
\hat{u}_{i}=x_{i} \widehat{u_{2}}+\mu_{1}, \\
\hat{u}_{N}=x_{2} \widehat{u_{N-1}}+\mu_{2},
\end{gathered}
$$

where the following notation:

$$
\begin{gathered}
x_{1}=\frac{\tau a_{2}}{h_{p}^{2} \Delta_{1}}, \quad \Delta_{1}=\frac{\tau}{h_{p}^{2}} a_{2}+\frac{1}{2} c_{1}+\frac{1}{h_{p}}\left(c_{n_{1}}+\frac{\tau}{R_{1}}\right), \\
\mu_{1}=\frac{1}{\Delta_{1}}\left\{\frac{1}{\mathrm{~h}_{p}}\left[c_{n_{1}} u_{1}+\tau\left(\frac{V_{1}}{R_{1}}+q_{n_{1}}\right)\right]+\frac{1}{2}\left[c_{1} u_{1}+\tau f_{p_{1}}\right]\right\}, \\
x_{2}=\frac{\tau a_{N}}{h_{p}^{2} \Delta_{2}}, \quad \Delta_{2}=\frac{\tau}{h_{p}^{2}} a_{N}+\frac{1}{2} c_{N}+\frac{1}{h_{p}}\left(c_{n_{N}}+\frac{\tau}{R_{N}}\right), \\
\mu_{2}=\frac{1}{\Delta_{2}}\left\{\frac{1}{h_{p}}\left[c_{n_{N}} u_{N}+\tau\left(\frac{V_{N}}{R_{N}}+q_{n_{N}}\right)\right]+\frac{1}{2}\left[c_{N} u_{N}+\tau f_{p_{N}}\right]\right\} .
\end{gathered}
$$

This system of equations is solved by the sweep method known, and reliable streaming option to apply this method, gives the best results for systems with highly changeable koeffig cents [5]. 


\section{Discussion}

The dependence of the thermal conductivity of concrete koeffitshenta the coordinates and direction, caused by the presence of steel reinforcement, can not be directly considered in the differential equations, as the grid spacing greater than the diameter of the reinforcing bar. Imagine that the rebar in concrete artificially allocated such that the total thermal resistance of the rod and the surrounding concrete is not changed. Suppose, for example, the rebar is located along a straight line of the family $G, f$ and has a cross section. Then the effective thermal conductivity kozffitsient determined from the equation

$$
\lambda_{B}\left(S^{\prime}-S_{A}\right)+\lambda_{A} S_{A}=\lambda^{\prime} S^{\prime},
$$

where

$\lambda_{\mathrm{B}}$ and $\lambda \mathrm{A}$ - concrete and steel thermal conductivity, $\mathrm{W} /\left(\mathrm{m}^{2}{ }^{\circ} \mathrm{C}\right)$;

$\mathrm{S}^{\prime}=\mathrm{h}_{2} \mathrm{~h}_{3}$ and $\lambda^{\prime}-$ column concrete area with the conditional distribution of valves, $\mathrm{m}^{2}$ and thermal conductivity of the concrete, $\mathrm{W} /\left(\mathrm{m}^{2}{ }^{\circ} \mathrm{C}\right)$.

Consequently,

$$
\lambda^{\prime}=\lambda_{B}+\left(\lambda_{\mathrm{A}}-\lambda_{B}\right) \frac{S_{\mathrm{A}}}{S^{\prime}}
$$

This value and must be submitted to the corresponding difference equation.

Recommended absence of VOC is absolutely stable and uniformly at a rate of $0\left(\tau+|h|^{2}\right)$. We do not recommend the use of explicit schemes, as a three-dimensional explicit scheme is stable only if $\tau<h^{2} / 6 \alpha$ restrictions (a - conductivity-temperature coefficient, $\mathrm{m}^{2} / \mathrm{s}$ ), which results in very small time step. In order to solve a particular problem for the present method is to beat the compiled program to calculate ovy then varying the control actions and to carry out calculations of the temperature field, select the most efficient mode of heat treatment.

There are a number of methods to search for the minimum of non-linear functions of several variables. Libraries of standard programs usually contain a program implementing one of these methods. For the independent preparation of such a program, you can recommend the most simple method of descent.

The above method of calculating the heat release function coefficients provides a function that best experimental data according heat intensity $\left(\frac{d Q}{d t}\right)$ temperature $(u)$ and concrete heat $(\mathrm{Q})$, positioning with a minimum of data. It suffices to have the results of only one of concrete heat dissipation experiment temperature mode, which covers the entire temperature range of interest. This is achieved through the use of the recommended method of mathematical processing of the experimental results.

\section{Conclusion}

Consider the example of the calculation of the temperature field of concrete for the area, which is about the size of parallelepiped, $0.48 \times 0.48 \times 2.7 \mathrm{~m}$ (fragment of a column). The lower part of the area previously occupied by the size $0.48 \times 0.48 \times 1.7 \mathrm{~m}$ laid concrete with a coefficient of relative heat $\omega_{0}=0.9$, and the upper part of the size $0.48 \times 0.48 \times 1 \mathrm{~m}$ takes concrete mix with $\omega_{0}=0,01$. On top of concrete covered with mat thickness $\mathrm{c}=0.05 \mathrm{~m}$ with a coefficient of thermal conductivity $\mathrm{d}=0,05 \mathrm{~W} / \mathrm{m}^{2}{ }^{\circ} \mathrm{C}$. The heat transfer coefficient of the outer surface of the structural $\alpha=25 \mathrm{~W} / \mathrm{m}^{2}{ }^{\circ} \mathrm{C}$, ambient temperature $\mathrm{U}_{\mathrm{B}}=-10^{\circ} \mathrm{C}[14$, $15]$.

We place the origin at the lower top of the box and send J-axis; up edge and the axis $\mathrm{X}_{1}$ and $\mathrm{X}_{2}$ horizontal at the base of the ribs. The heating formwork to the side faces, starting 
from a height $\mathrm{X}_{3}=1.5 \mathrm{~m}$. In concrete, the distance in the vertical direction through four lateral edges of the reinforcing rod diameter of $0.02 \mathrm{~m}$ at a distance of 0.06 meters from the lateral faces. Since the column is symmetric about the vertical axis passing through the center of the box to hold enough account for a quarter of the field, cut-out planes $\mathrm{X}_{1}=0.24$ $\mathrm{m}$ and $\mathrm{X}_{2}=0,24 \mathrm{~m}$. Heat flow through these planes will be zero. We introduce in the grid with steps $\mathrm{h}_{1}=0.03 \mathrm{~m}, \mathrm{~h}_{2}=0.03$ and $\mathrm{h}_{3}=0.06 \mathrm{~m}$, respectively, on the axes $\mathrm{X}_{1}, \mathrm{X}_{2}$ and $\mathrm{X}_{3}$. The total number of grid points $9 \times 9 \times 46=3726$. Rebar passes the nodes $(3,3, N)$ with $\mathrm{N}=$ $1, \ldots, 46$, so the thermal conductivity in the $\mathrm{X}_{3}$ direction in these nodes should be calculated from the formula (5)

$$
\lambda^{\prime}=\lambda_{B}\left[1+\left(\frac{\lambda_{\mathrm{A}}}{\lambda_{B}}-1\right) \frac{S_{\mathrm{A}}}{S^{\prime}}\right]
$$

Where $S_{\mathrm{A}}=3,14 *(0,01)^{2} \mathrm{~m}^{2} ; S^{\prime}=h_{1} h_{2}=(0,03)^{2} \mathrm{~m}^{2}$

Let us $\lambda_{\mathrm{A}}=40 \mathrm{~W} /\left(\mathrm{m}^{0} \mathrm{C}\right) ; \lambda_{\mathrm{B}}=\lambda_{\mathrm{o}}-\omega\left(\lambda_{\mathrm{o}}-\lambda_{1}\right)$;

$\lambda_{\mathrm{o}}=3 \mathrm{~W} /\left(\mathrm{m}{ }^{0} \mathrm{C}\right) ; \lambda_{1}=2,6 \mathrm{~W} /\left(\mathrm{m}^{0} \mathrm{C}\right)$. The coefficients in the equation of concrete heat release kinetics: $Q_{\max }=1,25 * 10^{5} \mathrm{~kJ} / \mathrm{M} 3 ; K=4,77 * 10^{-6} \mathrm{c}-1 ; u_{3}=-6,7^{\circ} \mathrm{C} ; \zeta=2,3 ; v$ $=2,2$.

Specific volume heat capacity of concrete $\mathrm{SB}=2000 \mathrm{~kJ} /\left(\mathrm{m}^{30} \mathrm{C}\right)$.

The initial value of the relative heat take $\omega_{0}=0,9$ in the nodes $(I, J, N)$ at $\mathrm{I} \leq \mathrm{N} \leq 29$ $\left(0 \leq \mathrm{x}_{3} \leq 1.7 \mathrm{~m}\right.$ - previously poured concrete) and $\omega_{0}=0,1$ in the nodes (I, J, N) at $29<\mathrm{N} \leq 46$ $\left(1,7<\mathrm{x}_{3}<2,7 \mathrm{~m}\right.$ - concrete). Suppose that the initial temperature of the concrete mix $u_{0}=$ $+5^{0} C$ B in the nodes (I, J, N) at $29<\mathrm{N} \leq 46$, and the initial temperature of the previously poured concrete $u_{0}=-9^{0} \mathrm{C}$ в sites $(\mathrm{I}, \mathrm{J}, \mathrm{N}), \mathrm{I} \leq \mathrm{N} \leq 29$.

Specific power heating formwork $\mathrm{q}_{\mathrm{n}}=\mathrm{I} \mathrm{kW} / \mathrm{m}^{2}$, the thickness of the insulation layer of the deck $\mathrm{d}=0,04 \mathrm{~m}$, the thermal conductivity of insulation material $\lambda_{u_{3}}=0,04 \mathrm{~W} /(\mathrm{m}$ $\left.{ }^{\circ} \mathrm{C}\right)$, and the specific heat of the deck $\mathrm{c}_{\mathrm{n}}=20 \mathrm{~kJ} /\left(\mathrm{m}^{2}{ }^{0} \mathrm{C}\right)$. Suppose the lower face of the box $1 / \mathrm{R}=0, \mathrm{c}_{\mathrm{n}}=0, \mathrm{q}_{\mathrm{n}}=0$. Heat flow is also zero in the plane $\mathrm{x}_{1}=0.24 \mathrm{~m}$ and $\mathrm{x}_{2}=0.24 \mathrm{~m}$.

On the open side faces of the heat exchange takes place: $1 / \mathrm{R}=\alpha=25 \mathrm{~kJ} /\left(\mathrm{m}^{20} \mathrm{C}\right), \mathrm{c}_{\mathrm{n}}=$ $20 \mathrm{~kJ} / \mathrm{m}^{2}, \mathrm{q}_{\mathrm{n}}=1 \mathrm{~kW} / \mathrm{m}^{2}$. On the upper face: $\mathrm{R}=1,04\left(\mathrm{~m}^{20} \mathrm{C}\right) / \mathrm{W}, \mathrm{c}_{\mathrm{n}}=0, \mathrm{q}_{\mathrm{n}}=0$.

Calculation of the temperature field for this task can be performed using a specialized computer program.

\section{References}

1. Shadanovsky B.V., Sinenko S.A., Brodske V.I. and other. Construction of a complex object. 5th International Scientific Conference «International, Partnership and Innovation in Construction Science and Education» p.10 28 November 2016.

2. Zhadanovsky Boris, Sinenko Sergey, Slavin Alexey. Processing of exterior light concrete wall panels. MATEC Web of Conferences Volume 193 (2018). International Scientific Conference Environmental Science for Construction Industry - ESCI 2018. Ho Chi Minh City, Vietnam, March 2-5, Published online: 20 August 2018 DOI: https://doi.org/ 10. 1051 / matecconf / 201819303017

3. Zhadanovskiy Boris, Sinenko Sergey, Guidelines on calculation of the concrete thermal treatment modes. MATEC Web of Conferences Volume 193 (2018) International Scientific Conference Environmental Science for Construction Industry ESCI 2018 Ho Chi Minh City, Vietnam, March 2-5, Published online: 20 August 2018 DOI:https://doi.org/10.1051/matecconf/201819303010

4. Novikov Sergey, Zhadanovsky Boris, Sinenko Sergey. Guidelines on calculation of the concrete thermal treatment modes 22nd International Conference on Innovative 
Manufacturing Engineering and Energy - IManE\&E 2018. MATEC Web of Conferences 178, 09007 (2018). IManE\&E 201822nd International Conference on Innovative Manufacturing Engineering and Energy - IManE\&E 2018 . MATEC Web $\begin{array}{lllll}\text { of Conferences } & 178, & 09007 & \text { (2018). IManE\&E }\end{array}$ https://doi.org/10.1051/matecconf/201817809007 A.O. Adamtsevich, Construction Materials 1, 53-57 (2015)

5. M.V. Volovik, Technology and organization of construction production 1(2), 14-18 (2013)

6. B. Zhadanovsky, S. Sinenko, International Journal of Applied Engineering Research 11(3), 1724-1727 (2016)

7. R. Kazaryan, On certain development aspects of an ipsas-based system-target approach to evaluation of net asset sustainability level projects in high-rise construction 33, (2018)

8. V. Khmel, S. Zhao, IATSS Research, International Association of Traffic and Safety Sciences, Tokyo 39-2, 138-145 (2016)

9. S. Staropoli, S. Staropoli, C. Staropoli, A. Yvrand-Billon, Review of Industrial Organization, Springer 35-1, 1-18 (2009)

10. T. Liu, Y. Wang, S. Wilkinson, A comparative analysis of Australia and China International Journal of Project Management, Elsevier 34-4, 701-716 (2016)

11. Y. Wang, Public Administration Review, Wiley 69-4, 779-782 (2009)

12. Y. Jingfeng, Y.A. Zeng, J.M. Skibniewski, Q. Li, Construction Management and Economics, Taylor \& Francis (Routledge) 27-3, 253-270 (2009)

13. C. Cui, Y. Liu, A. Hope, International Journal of Project Management, Elsevier 36-5, 773-794 (2018)

14. A. Chaurey, P.R. Krithika, D. Palit, S. Rakesh, K.B. Sovacool, Energy Policy, Elsevier 47, 48-55 (2012)

15. Z. Wang, A. He, G. Shi, G. Mei, Temperature effect on AE energy characteristics and damage mechanical behaviors of granite. International Journal of Geomechanics, 18(3) (2018)

16. B. Zhadanovsky, S. Sinenko, Pressure method of monolithic concrete structures of buildings and structures. International Journal of Applied Engineering Research, 11(3) 1724-1727 (2016) 